\title{
Synthesis and Characterization of Modified Sepiolite for the Adsorptive Removal of Rhodamine B from Wastewater
}

\author{
Zhang Jianshu ${ }^{1,2}$, Shaomin Liu ${ }^{1,2 *}$, Wang Xiaoiao ${ }^{1,2}$ and Xu Pengpeng ${ }^{1,2}$ \\ ${ }^{1}$ Key Laboratory of Safe and Effective Coal Mining (Anhui University of Science and Technology), Ministry of Education, China \\ ${ }^{2}$ School of Earth Science and Environmental Engineering, Anhui University of Science and Technology, Huainan, China
}

*Corresponding author: Shaomin Liu, School of Earth Science and Environmental Engineering, Key Laboratory of Safe and Effective Coal Mining, Anhui University of Science and Technology, China.

Received Date: November 10, 2019

Published Date: November 15, 2019

\begin{abstract}
SDS/sepiolite was successfully synthesized as a low-cost adsorbent used in removal of Rhodamine B (RhB) from aqueous solution. The adsorbing capacity of RhB onto SDS/sepiolite shows a significant increase than the acid sepiolite. Analysis of the specific surface area, morphology, microstructure, chemical structure, chemical bonding substance and functional groups by BET, SEM, FT-IR proved the better adsorption capacity of SDS/sepiolite. The adsorption quantity was calculated to be $24.91 \mathrm{mg} / \mathrm{g}$ under the optimum condition: SDS/sepiolite loadings of $0.02 \mathrm{~g}$, $\mathrm{pH}$ of 3 and $50{ }^{\circ} \mathrm{C}$, the concentration of RhB is $35 \mathrm{mg} / \mathrm{L}$. obtained by analysis of influencing factors. It was found that a pseudo-second-order equation provided the best correlation to the process of adsorption, $\mathrm{R}^{2}=0.999$. Adsorption isotherm was fitted with Langmuir equation on different temperature, all $\mathrm{R}^{2}>0.99$. Re-adsorption showed SDS/sepiolite has reusable capacity in the adsorption of $\mathrm{RhB}$ in environmental protection.
\end{abstract}

Keywords: Sepiolite; Rhodamine B (RhB); Sodium dodecyl sulfate (SDS); Adsorption isotherm

\section{Introduction}

It is well known that Rhodamine B (RhB) was widely used in leather, textile, paper industries. "Blood River" event, the river becomes red dyed by Printing and dyeing wastewater in Wenzhou, Zhejiang Province in July 2014. HeNan Ruyang "Red River" event is caused by the dyeing wastewater which penetrate land from the dyestuff plant nearby in September 2014. At the same time,a giant sewage pools discovered in Inner Mongolia, Ningxia Ming sheng dyeing co, LTD and other dye production companies involved among them. RhB as a typical kind of alkaline dye, has a structure of triphenylmethane molecules. $\mathrm{RhB}$ is a toxic kind of carcinogenicity and has great destructive to the environment [1-3]. RhB solution, migrated by diffusion and water removal, physical and chemical migrated through a series of biochemical reactions such as oxidation - reduction, hydrolysis and dissolve the precipitate, complexation-chelation, bio-analysis, photo-degradation, and biological organisms migrated through the absorption, metabolism, growth, and death process, appeared in soil, groundwater, plants, animals, and eventually caused human health problems through the food chain and other sectors.
Sepiolite is a kind of two-layer silicon-oxygen tetrahedron, the middle layer of magnesium oxide octahedral structure. And a layered structure of a chain. Each of the six-top silicon-oxygen tetrahedron vertex opposite, forming a layered structure on the key elements 2:1 parallel channel arranged in the lower phase [4-6]. $\mathrm{Mg}^{2+}$ and $\mathrm{Si}-\mathrm{OH}$ groups are the main active centers for adsorption [7]. This particular structure determines its excellent adsorption performance, better stability also determines sodium dodecyl sulfate (SDS) supported on sepiolite better stability [8,9]. However, due to natural sepiolite impurities, contaminants and partially blocked pores smaller channels which limits the role of sepiolite [2]. Therefore, sepiolite it has been studied using the modified method by scholars. Marjanović V [4], Letaief S [11], Miura A [12], Franco F, et al. [13] studied the adsorption capacity of sepiolite acid modified. Miura A [12] Duan E, et al. [14] studied the adsorption capacity of sepiolite heated-modified. Franco F, et al. [13] researched on the Microwave assisted acid treatment of sepiolite. Zhang G, et al. [15], Lazarević S, et al. [16], Pina-Zapardiel R, et al. [17] studied the adsorption and catalysis capacity of sepiolite loaded metal 
or metallic oxide. Adsorption capacity of sepiolite loaded anionic surfactants has been studied by few people.

SDS as an anionic surfactant was used to modify sepiolite in this article. Adsorption capacity to RhB with SDS/sepiolite was compared with sepiolite, acid sepiolite and Polyvinylpyrrolidone (PVP)/sepiolite in the present study. Then the obtained SDS/ sepiolite was characterized using Brunauer-Emmett-Teller (BET), scanning electron microscopy (SEM), and fourier transform infrared spectroscopy (FT-IR). To evaluate the potential of SDS/sepiolite, studies of the kinetics, adsorption mechanisms and isotherms were conducted. Adsorption mechanisms was tested under the optimum conditions obtained by analyzing the influence factors. Finally, Readsorption experiments executed was detected to showed whether there is recycling of SDS/sepiolite. All results indicated that SDS/ sepiolite is a good adsorbent using in the environmental field.

\section{Experimental Section}

\section{Activation of sepiolite}

All chemical reagents in this study were of analytical grade and used without further purification. A certain amount of sepiolite was immersed into $10 \%$ dilute nitric acid for $6 \mathrm{~h}$. Afterward, the solid was filtered, dried, and calcined at $120^{\circ} \mathrm{C}$ for $12 \mathrm{~h}$. Finally, the 100 150 um particle was chosen as carrier.

\section{Synthesis of SDS/sepiolite and PVP/sepiolite composites}

In the synthesis of SDS/sepiolite composites, $5.0 \mathrm{~g}$ of sepiolite powder and $0.5 \mathrm{~g}$ of SDS were added into $85 \mathrm{ml}$ of water-ethanol solution (deionized water: absolute ethanol= 75:10, v/v), stirred for $30 \mathrm{~min}$. Added some hydrochloric acid(0.1M) until pH=2, stirred for $4 \mathrm{~h}$ on magnetic stirrer and then let stand for $1 \mathrm{~h}$, removed of the supernatant, repeat three times, then the mixed solution was centrifuged using a centrifuge. The sediment at $120^{\circ} \mathrm{C}$ for $12 \mathrm{~h}$. Finally, the 100-150 um particle was chosen as adsorption carrier.

Synthesis of PVP/sepiolite accord to the way of synthesis of SDS/sepiolite. And then adsorption capacity to RhB with SDS/sepiolite was compared with sepiolite, acid sepiolite and Polyvinylpyrrolidone (PVP)/sepiolite.

\section{Characterization of adsorbents}

The specific Brunauer-Emmett-Teller (BET) surface area (SBET) for each composite was derived from $\mathrm{N}_{2}$ adsorption isotherms that were measured using a BELSORP. The morphologies and microstructure analyses were performed with a JSM-6700F field-emission scanning electron microscope. Fourier transform infrared (FT-IR) spectra(400-4000 $\mathrm{cm}^{-1}$ ) were recorded on a MAGNA-IR 750 FT-IR apparatus using KBr disks.

\section{Analysis of factors affecting the adsorbent}

Adsorption reactions were conducted in some $25 \mathrm{ml}$ Serum bottles, $\mathrm{m}(\mathrm{g})$ of SDS/sepiolite and $15 \mathrm{ml} \mathrm{RhB(C-mg/L)} \mathrm{were} \mathrm{added,}$ adjusted $\mathrm{pH}$, sampling $20(\mathrm{~min}), 40(\mathrm{~min}), 1 \mathrm{~h}, 1.5 \mathrm{~h}, 2 \mathrm{~h}, 3 \mathrm{~h}$ and $5 \mathrm{~h}$ after adsorption reactions. Absorbance of samples were detected at $554 \mathrm{~nm}$ using a visible spectrophotometer. specific figures were seen in the Table 1.
Table 1: The N2 absorption-desorption parameters of adsorbent.

\begin{tabular}{|c|c|c|c|}
\hline \multirow{2}{*}{ Catalysts } & $\begin{array}{c}\text { BET Surface } \\
\text { Area }\end{array}$ & Pore Volume & Pore Size \\
\cline { 2 - 4 } & $\mathbf{( \mathbf { m } ^ { 2 } / \mathbf { g } )}$ & $\mathbf{( \mathbf { c m } ^ { 3 } / \mathbf { g } )}$ & $\mathbf{( n m )}$ \\
\hline Sepiolite & 31.48 & 0.0901 & 12.39 \\
\hline SDS/sepiolite & 44.82 & 0.1178 & 12.77 \\
\hline
\end{tabular}

\section{Adsorption kinetics and isotherm of adsorption}

Adsorption kinetics: To determine the effect of SDS/sepiolite and the adsorption rate of $\mathrm{RhB}$, experiment were performed under the optimum condition that $\mathrm{m}_{\mathrm{SDS} / \mathrm{sep}}-0.02 \mathrm{~g}, \mathrm{C}_{\mathrm{RhB}}-35 \mathrm{mg} / \mathrm{L}, \mathrm{pH}-3$, sampling $0.5 \mathrm{~h}, 1 \mathrm{~h}, 1.5 \mathrm{~h}, 2 \mathrm{~h}, 3 \mathrm{~h}, 4 \mathrm{~h}, 6 \mathrm{~h}, 8 \mathrm{~h}$ and $10 \mathrm{~h}$ after adsorption reactions. Absorbance of samples were detected at 554nm using a visible spectrophotometer. Adsorption quantity was obtained by Eq.1. The kinetic data were tested using the pseudo-first (Eq.2) and pseudo-second (Eq.3) order and Morries-Wede (Eq.4) equations.

$$
\begin{aligned}
\mathrm{q}_{\mathrm{t}} & =\frac{\left(c_{1}-c_{2}\right) v}{m} \\
\frac{\mathrm{d} q_{t}}{d_{t}} & =k_{1}\left(q_{e}-q_{t}\right) \\
\frac{\mathrm{dq}_{\mathrm{t}}}{\mathrm{d}_{\mathrm{t}}} & =k_{2}\left(q_{e}-q_{t}\right)^{2} \\
\mathrm{q}_{t} & =k_{p} t^{0.5}+c
\end{aligned}
$$

Where, $\mathrm{q}_{\mathrm{t}}$ and $\mathrm{q}_{\mathrm{e}}(\mathrm{mg} / \mathrm{g}$ ) are the amounts of RhB adsorbed on the SDS/sepiolite at time t and at equilibrium, respectively. $\mathrm{C}_{1}$ and $\mathrm{c}_{2}$ are concentration of $\mathrm{RhB}$ before and after the reaction, respectively. $\mathrm{K}_{1}, \mathrm{k}_{2}$ and $\mathrm{k}_{\mathrm{p}}$ are adsorption rate constants in the pseudo-first and pseudo-second order and Morries-Wede equations.

Isotherms of adsorption: Isotherms of $\mathrm{RhB}$ adsorption on the SDS/sepiolite were determined in batch experiments. $0.02 \mathrm{~g}$ of SDS/ sepiolite with twelve different $\mathrm{RhB}$ concentrations $(10,13,15,18$, $20,23,25,28,30,33,35$ and $38 \mathrm{mg} / \mathrm{L}$ ) was added into $25 \mathrm{ml}$ Serum bottles. Adsorption reaction were conducted at 10, 25 and 35 degrees Celsius in the constant temperature water bath. Sampling $10 \mathrm{~h}$ after adsorption reactions and absorbance of samples were detected at $554 \mathrm{~nm}$ using a visible spectrophotometer. The equilibrium adsorption data were analyzed using the Freundlich (Eq.5) and Langmuir (Eq.6) equilibrium isotherms.

$$
\begin{aligned}
\mathrm{q}_{e} & =k c_{e}^{1 / n} \\
\frac{\mathrm{q}_{e}}{q_{m}} & =\frac{b_{e}}{1+b_{e}}
\end{aligned}
$$

$\mathrm{q}_{\mathrm{e}}$ is theamount of $\mathrm{RhB}$ adsorbed (mg/g), $\mathrm{c}_{\mathrm{e}}$ is $\mathrm{RhB}$ concentration in equilibrium solution ( $\mathrm{mg} / \mathrm{L})$.

\section{Re-adsorption experiments}

Adsorption reactions were conducted in some $500 \mathrm{ml}$ beaker, $0.3 \mathrm{~g}$ of SDS/sepiolite and $150 \mathrm{ml} \mathrm{RhB}(25 \mathrm{mg} / \mathrm{L})$ were added. Adsorption reaction were conducted at 25 degrees Celsius in the 
constant temperature water bath. sampling $0.5 \mathrm{~h}, 1 \mathrm{~h}, 1.5 \mathrm{~h}, 2 \mathrm{~h}, 2.5 \mathrm{~h}$, $3 \mathrm{~h}, 3.5 \mathrm{~h}$ and $4 \mathrm{~h}$ after adsorption reactions. Then removing of the supernatant and filtrating the sediments with vacuum suction filter machine. And then conducting adsorption reaction $\left(\mathrm{m}_{\mathrm{SDS}}\right.$ / ${ }_{\text {sep }}: \mathrm{V}_{\mathrm{RhB}}=1: 500$ (g:ml)) two times. Absorbance of samples were detected at $554 \mathrm{~nm}$ using a visible spectrophotometer.

\section{Results and Discussion}

\section{Adsorption performance comparison}

The absorption quantity at different adsorption time with several different absorbents were shown in Figure 1. As can be seen from Figure 1, SDS/ sepiolite has a strong adsorption capacity, with physical adsorption and chemical adsorption. acid sepiolite, the absorption quantity increased with time rising, rising from 11.88 at $0.5 \mathrm{~h}$ to 12.15 at $4 \mathrm{~h}$. at the beginning of $4 \mathrm{~h}$, adsorption is mainly based on physical adsorption with a fast increased rate, since the sepiolite surface charge is determined by the hydrolyzed ruptures of the Si-O bond and Al-O bond on the surface, which can become both acid and alkali. The hydroxyl groups in $\mathrm{R}-\mathrm{OH}(-\mathrm{OH})$ generated by the hydrolyzed bond breaking have both acid and alkali properties. The modified effect is mainly to make the structural and surface charges of sepiolite in aqueous solution change and thus change the charge and adsorbing activity of sepiolite colloid.

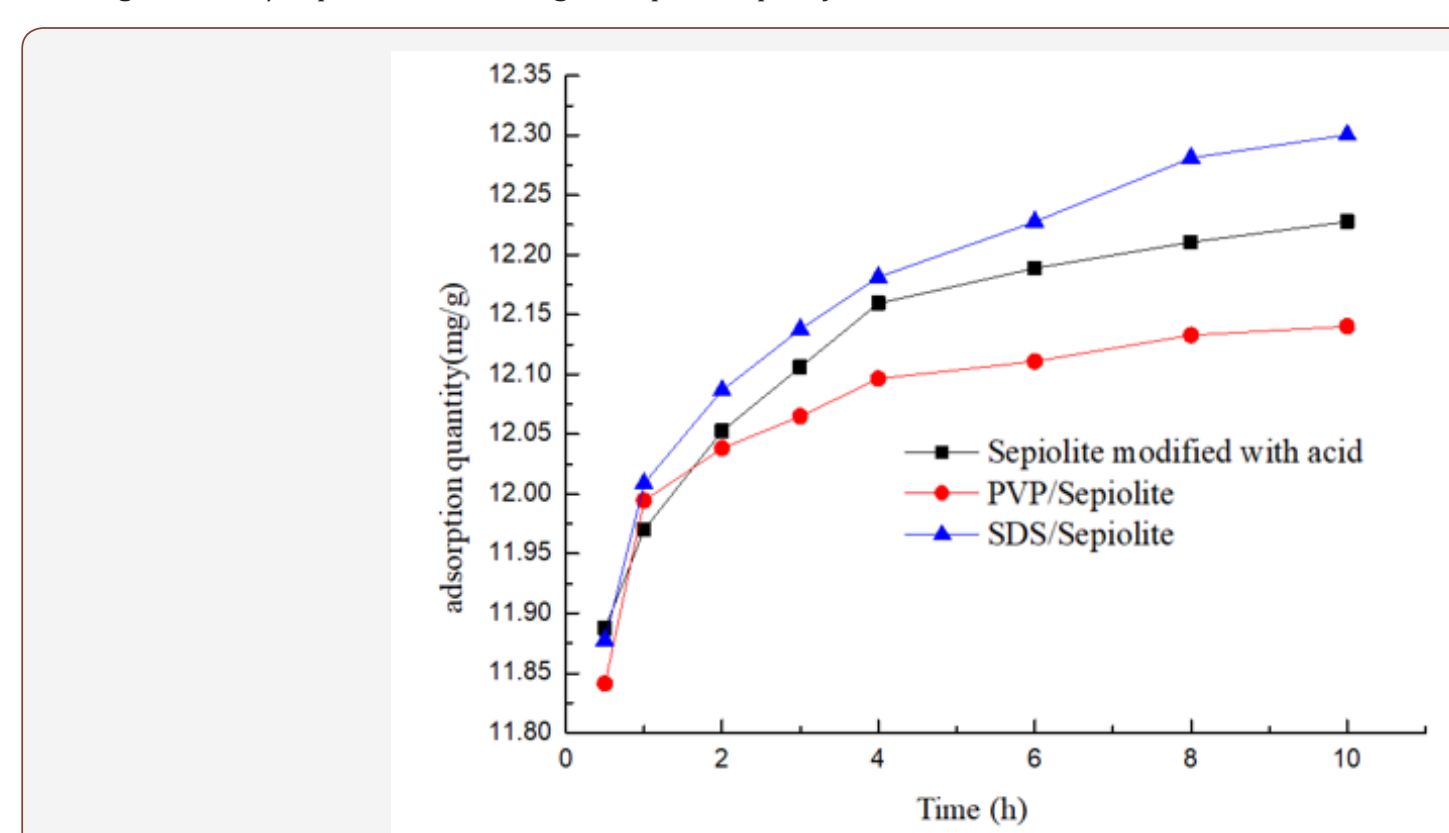

Figure 1: Comparison of Adsorption of modified sepiolite.

The modified PVP and SDS surface made plug some of the surface micro pores, however, the surface modified adsorption rate slope of PVP and SDS was the biggest, In the adsorption of 1 hours, the adsorption value is higher than that of acid modified sepiolite, PVP/ sepiolite adsorption slope is more than SDS/ sepiolite adsorption slope, may PVP of high surface activity and more load on the surface of sepiolite, In the adsorption of PVP in the time zone contact with the RhB large area, with more quantities. In 3 hours, the several sepiolites' adsorption slope is close, subsequently adsorbed slope of PVP/Sepiolite is minimum, acid modified sepiolite is second, SDS/sepiolite is maximum, because PVP and RhB in the sepiolite surface reaction together, to some extent hindered the sepiolite adsorption of RhB, which is the reason, the absorbance of PVP/ Sepiolite adsorption of RhB than acid change high absorbance of sepiolite adsorption of RhB at 10 hours.

\section{Structural characterization}

Figure 2 shows the nitrogen adsorption isotherm for the acid sepiolite and SDS/sepiolite, exhibiting slow adsorption and desorption (type III isotherm). the date indicates that SDS/sepiolite has a better adsorption capacity to the $\mathrm{N}_{2}$ than acid sepiolite. The nitrogen adsorption capacity increases with the increase of the relative pressure, the growth rate is slower, mainly because at the start of the sepiolite surface contains a large number of microporous and internal pore contains a certain amount of material jam and relatively low pressure. When the relative pressure $\mathrm{p} / \mathrm{p}_{0}$ is in the range of $0.2-1$, the nitrogen adsorption speed accelerated, which is because of the modified results and the relative pressure. When the relative pressure $\mathrm{p} / \mathrm{p}_{0}$ is $0.03-0.2$, the difference of two kinds of modified sepiolite adsorption quantity is not obvious. on the one hand, at the time, this pressure is small, unable to make a large amount of nitrogen into the sepiolite pore. on the other hand, the pore of the modified sepiolite caused the sepiolite void clog, when the relative pressure $\mathrm{p} / \mathrm{p}_{0}$ is $0.2-1$, SDS/sepiolite adsorption quantity was greater than the acid modified sepiolite. Meanwhile, the BETspecific surface area of acid sepiolite was $31.4764 \mathrm{~m}^{2} / \mathrm{g}$, which was smaller than that of the SDS/sepiolite $\left(44.81 \mathrm{~m}^{2} / \mathrm{g}\right)$, because the method of Adsorbent preparation and the concentration of SDS affect the specific surface area and the total pore volume of adsorbnet (Table 1).

The morphology and microstructure of the acid sepiolite and SDS/sepiolite composites were characterized by SEM. Figure 3(a) shows that the obtained acid sepiolite exhibited tube-like 
structure with diameters of approximately $2 \mathrm{um}$. Structure is relatively smooth and the other substances clogging the adsorption of pollutants contained in the tubular structure [17-19]. SDS loaded in the surface and inner of sepiolite which lead to the tight junctions and uneven shape in Figure 3(b). Entire surface of SDS / sepiolite was irregular and the total surface area becomes large. The change of original crystal structure into a tabular crystals can be seen in the Figure 3(b).Chemical structure, chemical bonding substance and functional groups of acid sepiolite and SDS/sepiolite were characterized by FT-IR. Peaks were found at 478-489, 624$677,1025-1089,1384-1425,2350-2411,3430-3429$ for both acid sepiolite and SDS/sepiolite. Significant shift of absorption peaks to SDS/sepiolite were seen Figure 4. Some shifts of their position were confirmed due to the structural changes of sepiolite by heating [20]. Solo peaks were found at 2927 and 2839 for SDS/sepiolite. It indicated that SDS successfully supported on sepiolite. Acid sepiolite and SDS/sepiolite exhibit various bands at 624-677(bending vibration of $\mathrm{Mg}-\mathrm{OH}$ ), at 753-795 (bending vibration of $\mathrm{Mg}-\mathrm{Fe}-\mathrm{OH}$ ) [21], which shows the basic structure of sepiolite has not changed because magnesium ions as a supporting role has not changed in sepliote [12]. SDS/sepiolite exhibits the band at 2839-2927 (asymmetric stretching vibrations of C-H groups) [21].

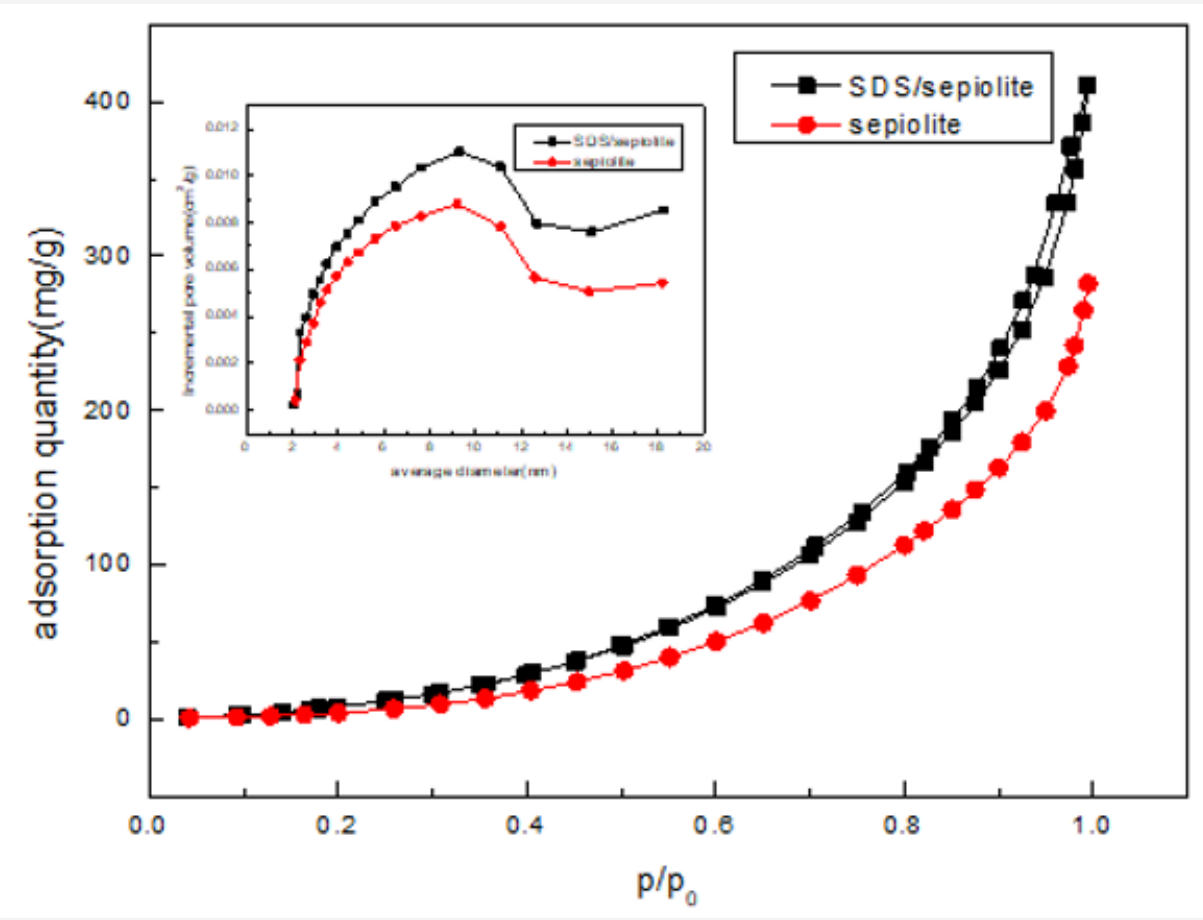

Figure 2: Analysis of SDS/sepiolite BET (a: comparison of adsorption isotherm of acid sepiolite and SDS/sepiolite to N2; b: the relation of particle of cumulative pore volume).

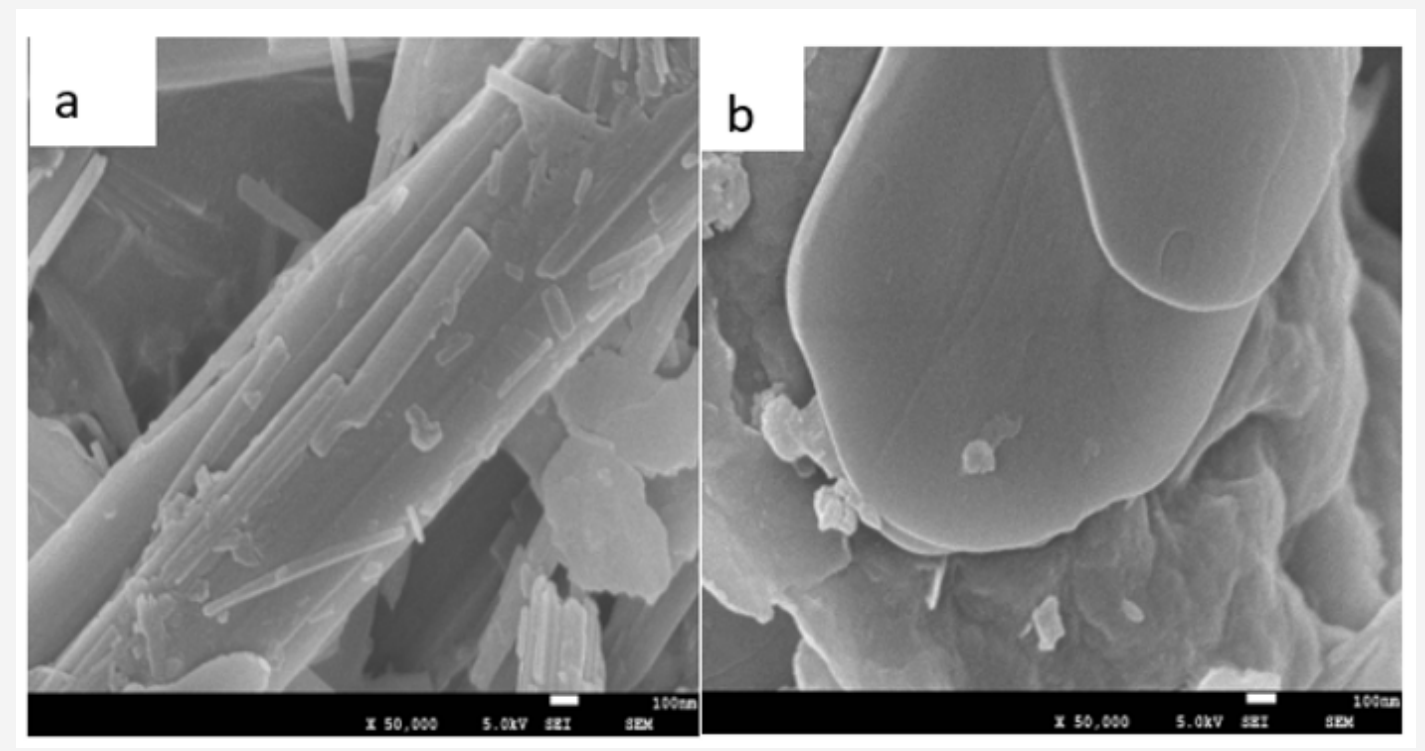

Figure 3: (a) SEM of acid sepiolite and (b) SDS/sepiolite. 


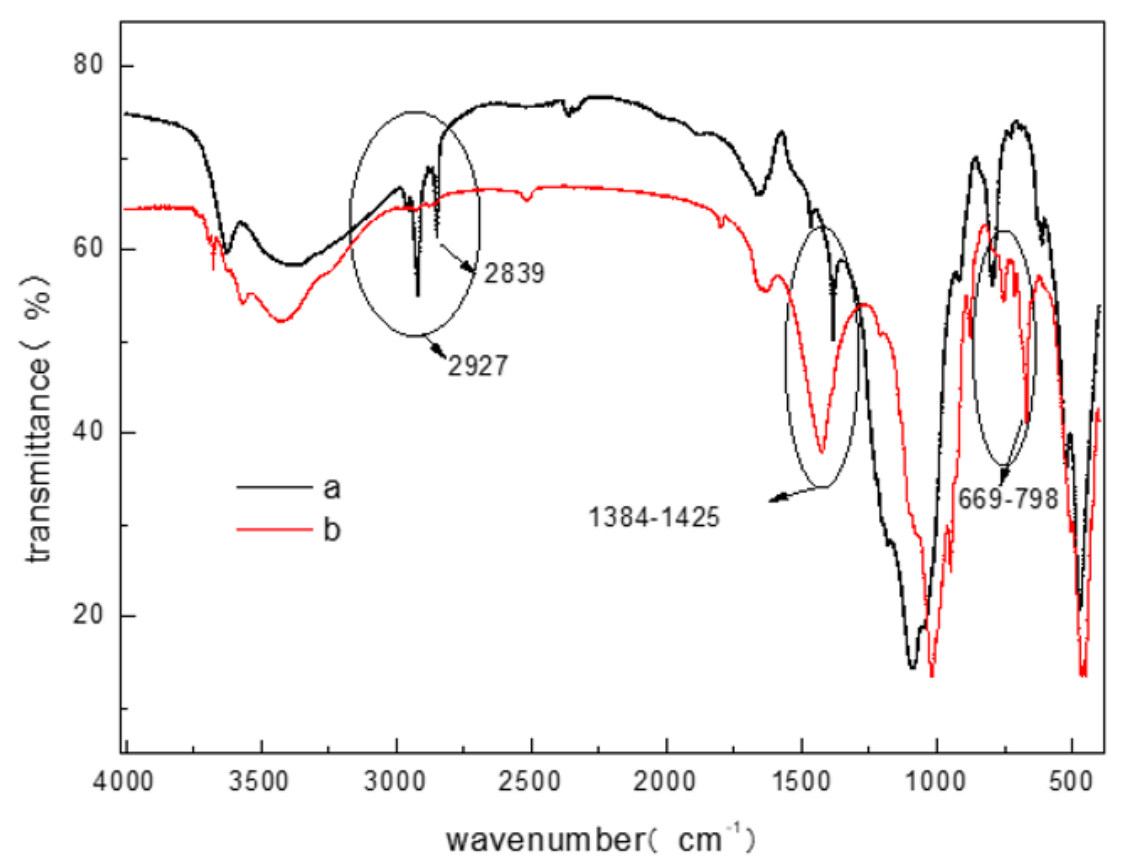

Figure 4: FTIR spectra of (a) SDS/sepiolite and (b) acid sepiolite.

\section{Analysis of factors affecting}

The effects of the SDS/sepiolite dosage on the reaction rate and adsorption quantity are shown in Figure 5 . The best date of adsorption quantity was $16.91 \mathrm{mg} / \mathrm{g}$ when the SDS/sepiolite dosage was $0.02 \mathrm{~g}$. The adsorption quantity was only $7.44 \mathrm{mg} / \mathrm{g}$ corresponding $\mathrm{m}_{\mathrm{SDS} / \text { sepiolite }}=0.05 \mathrm{~g}$. The maximum adsorption quantity was $7.5 \mathrm{mg} / \mathrm{g}$ on $0.05 \mathrm{~g}$ adsorbent in theory, it is very close to experimental data, thus it indicated a small number of adsorption quantity because of low RhB concentration. The reason of the low adsorption quantity of dosage $(0.03 \mathrm{~g}$ and $0.04 \mathrm{~g})$ is like this. The maximum adsorption quantity on $0.02 \mathrm{~g}$ SDS/sepiolite was 18.75 in ideal model, which indicated there some mass RhB unabsorbed in solution. Thus, $0.02 \mathrm{~g}$ of SDS/sepiolite was appropriate. Then the date of adsorption quantity to different $\mathrm{RhB}$ concentration verified the explanation in Figure 6.

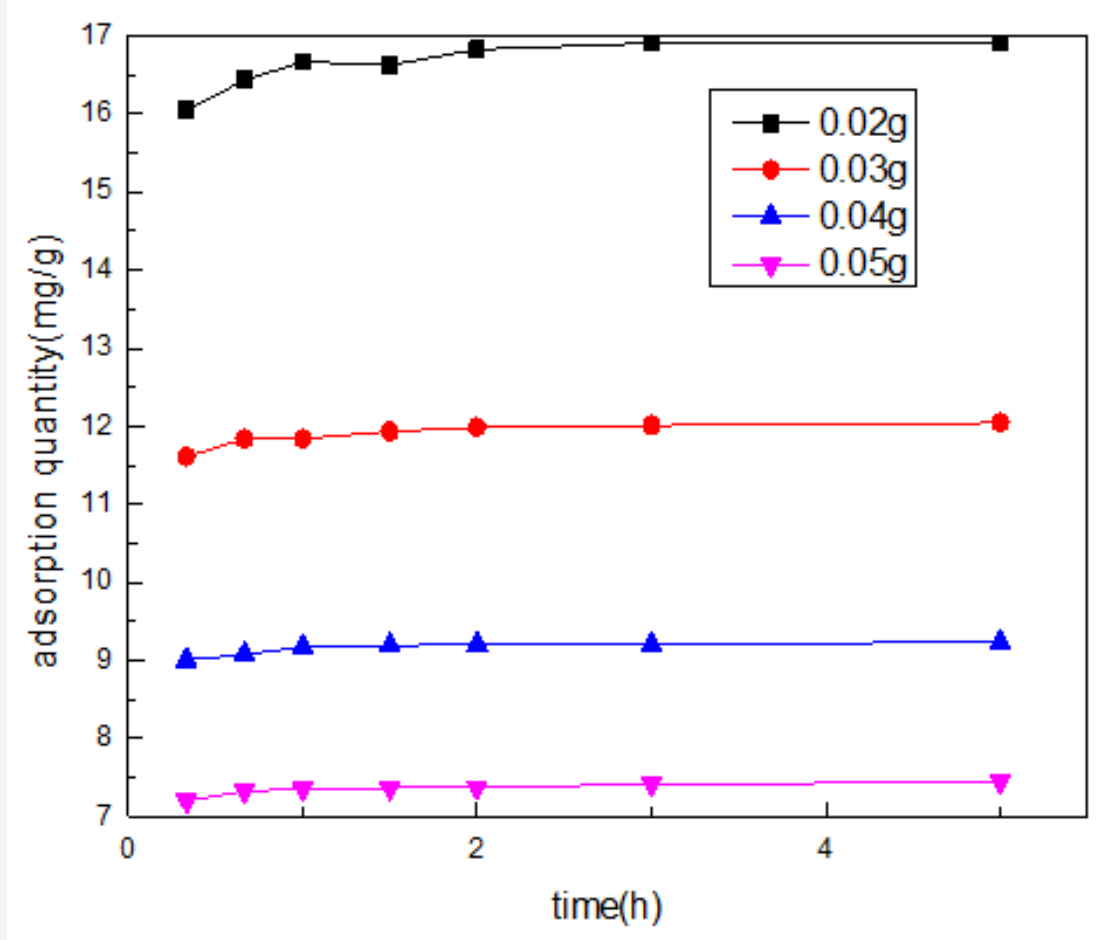

Figure 5: Effect of the adsorption capacity on different dosage. 


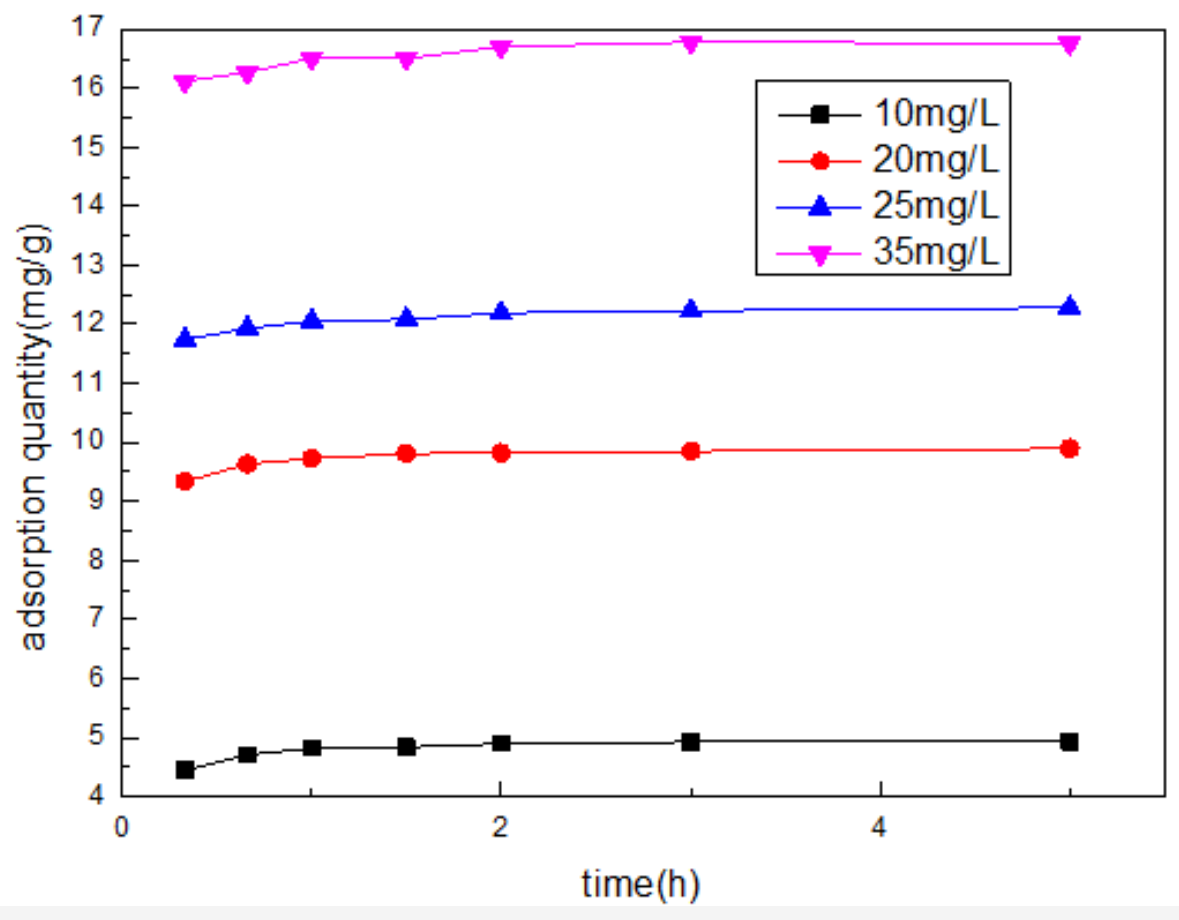

Figure 6: Effect of the adsorption capacity on different RhB concentration.

To compare the $\mathrm{pH}$ dependencies of the activities of SDS/ sepiolite, its relative activities were determined in the $\mathrm{pH}$ range 3-9 and the results were shown in Figure 7. The data showed that optimum $\mathrm{pH}$ is 3. Magnesium ions of octahedral layer was easily replaced by hydrogen ion in acid solution and the structure of sepiolite remains unchanged. Magnesium ions are eluted, and Si-O-Mg-O-Si formed two Si-OH which become active centers of adsorption. Besides, internal channels are through, microporous empty and microporous extended due to eluted magnesium ions in sepiolite $[4,12,13,16]$. In light of this theory, the maximum adsorption quantity was obtained in the solution $\mathrm{pH}=3$ (Table's 2\&3).

Table 2: Orthogonal design table.

\begin{tabular}{|c|c|c|c|}
\hline \multirow{2}{*}{ Level } & A & B & C \\
\cline { 2 - 4 } & $\begin{array}{c}\text { SDS/ } \\
\text { Sepiolite(g) }\end{array}$ & $\begin{array}{c}\text { RhB Concentration } \\
\text { (mg/L) }\end{array}$ & Solution pH \\
\hline 1 & 0.02 & 20 & 3 \\
\hline 2 & 0.03 & 25 & 5 \\
\hline 3 & 0.04 & 35 & 7 \\
\hline
\end{tabular}

Table 3: Orthogonal experiment results of adsorbing capacity.

\begin{tabular}{|c|c|c|c|c|}
\hline \multirow{2}{*}{ Number } & A & B & $\mathrm{C}$ & \multirow{2}{*}{$\begin{array}{l}\text { Adsorption Quantity } \\
\text { (mg/g) }\end{array}$} \\
\hline & SDS/Sepiolite(g) & RhB Concentration(mg/L) & Solution pH & \\
\hline 1 & 1 & 1 & 3 & 14.18967379 \\
\hline 2 & 1 & 2 & 2 & 21.44181221 \\
\hline 3 & 1 & 3 & 1 & 24.91114541 \\
\hline 4 & 2 & 1 & 2 & 9.746524363 \\
\hline 5 & 2 & 2 & 1 & 14.85101503 \\
\hline 6 & 2 & 3 & 3 & 16.74594116 \\
\hline 7 & 3 & 1 & 1 & 7.435646577 \\
\hline 8 & 3 & 2 & 3 & 11.14919634 \\
\hline 9 & 3 & 3 & 2 & 12.86199281 \\
\hline K1 & 20.18087714 & 10.45728158 & 15.73260234 & \\
\hline K2 & 13.78116019 & 15.81400786 & 14.68344313 & \\
\hline K3 & 10.48227858 & 18.17302646 & 14.59920259 & \\
\hline range & 9.698 & 7.716 & 1.133 & \\
\hline Pri and Sec Opt levels & & A1B3C1 $\mathrm{A}>\mathrm{B}>\mathrm{C}$ & & \\
\hline
\end{tabular}




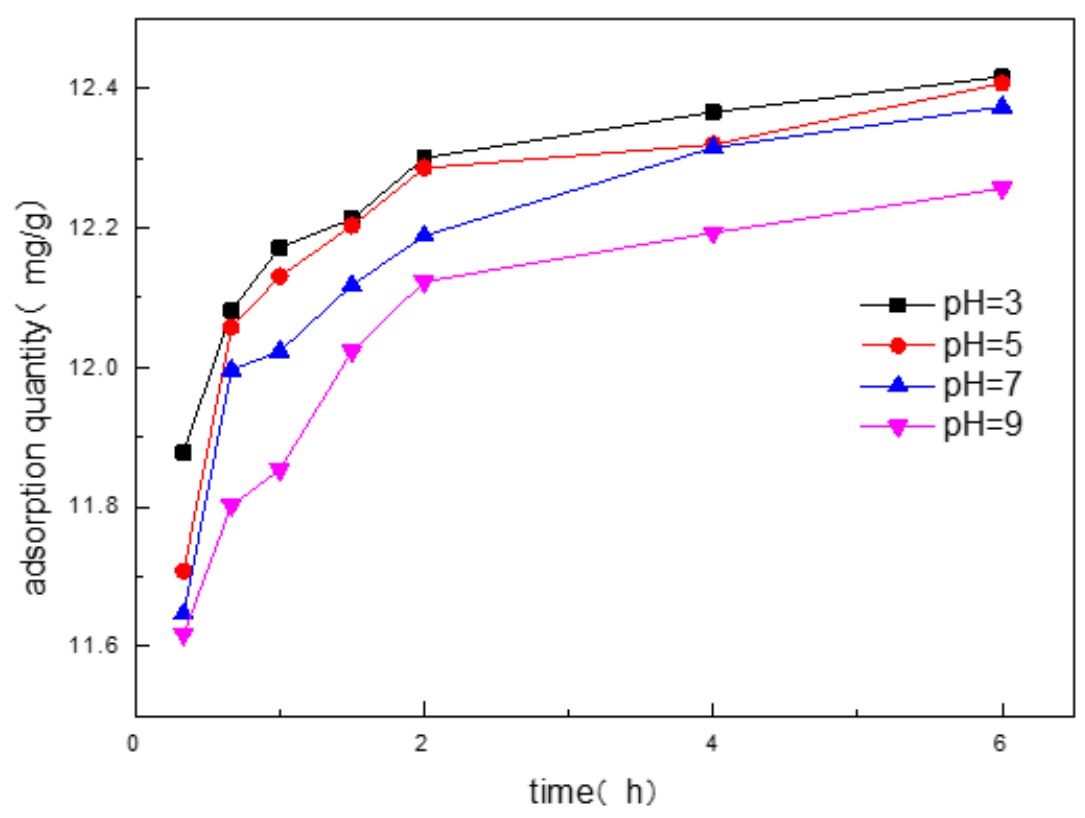

Figure 7: Effect of the adsorption capacity on different solution $\mathrm{pH}$.

Moreover, The surface charge of SDS/sepiolite becomes dependent on the $\mathrm{pH}$ of the solution due to protonation and deprotonation. Figure 8 is Zeta potential distribution of SDS/ sepiolite at varied pH. From Figure 8, we can know that the $\mathrm{pH}$ at zero-point charge of SDS/sepiolite is around 5, indicating that the surface charge is positive when $\mathrm{pH}<5$ and negative at $\mathrm{pH}>5$. The results indicate that SDS/sepiolite has a better adsorption effect on $\mathrm{RhB}$ under acidic conditions.

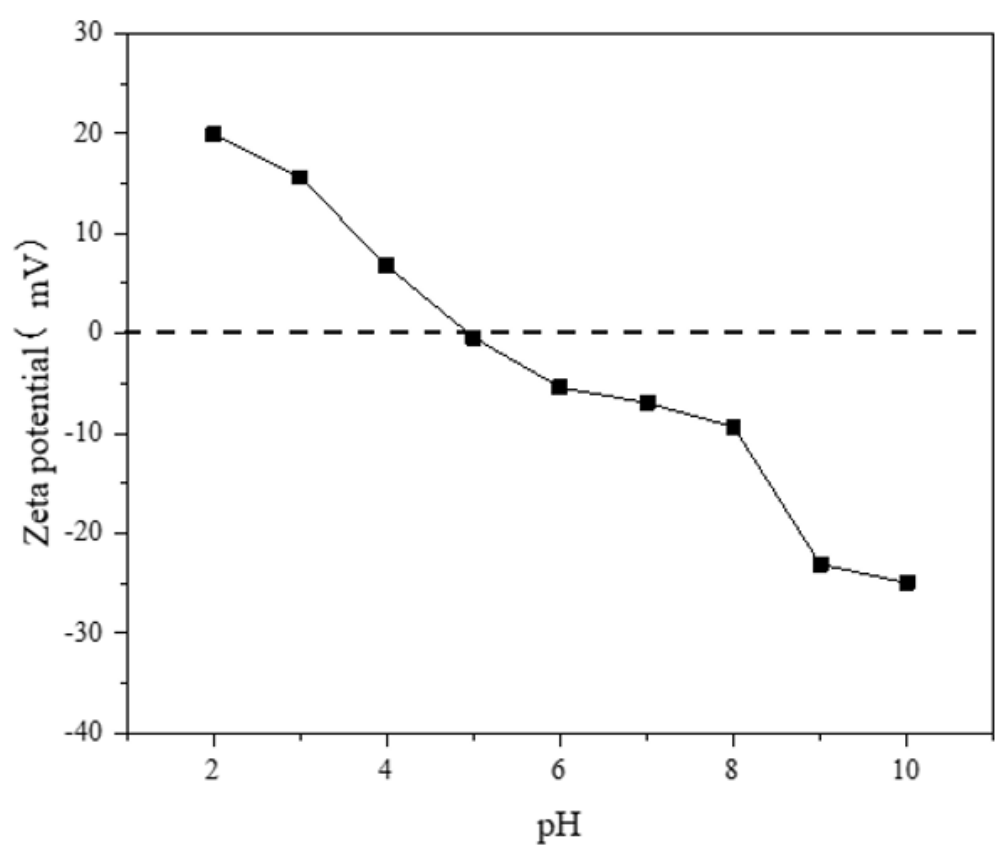

Figure 8: Zeta potential of SDS/sepiolite.

\section{Adsorption kinetics}

The kinetics of RhB adsorption under the optimum condition is presented in Figure 9. The $\mathrm{R}_{2}$ of pseudo-first, pseudo-second order and Morries-Wede equations were 0.705, 0.999 and 0.707, respectively. Equilibrium adsorption capacity obtained from the pseudo-second order was closed to the experimental data. In summary, adsorption process can be good fitted pseudo-second order. The assuming rate-limiting step was chemical adsorption in pseudo-second adsorption kinetics. With diffusion within the adsorbent and adsorption in the pores, the concentration of adsorbate become lower and lower. The tangent of line fitted Morries-Wede equation didn't pass the $x$-axis and y-axis intersection which indicated there are little inner adsorption in the adsorption process [22,23]. 

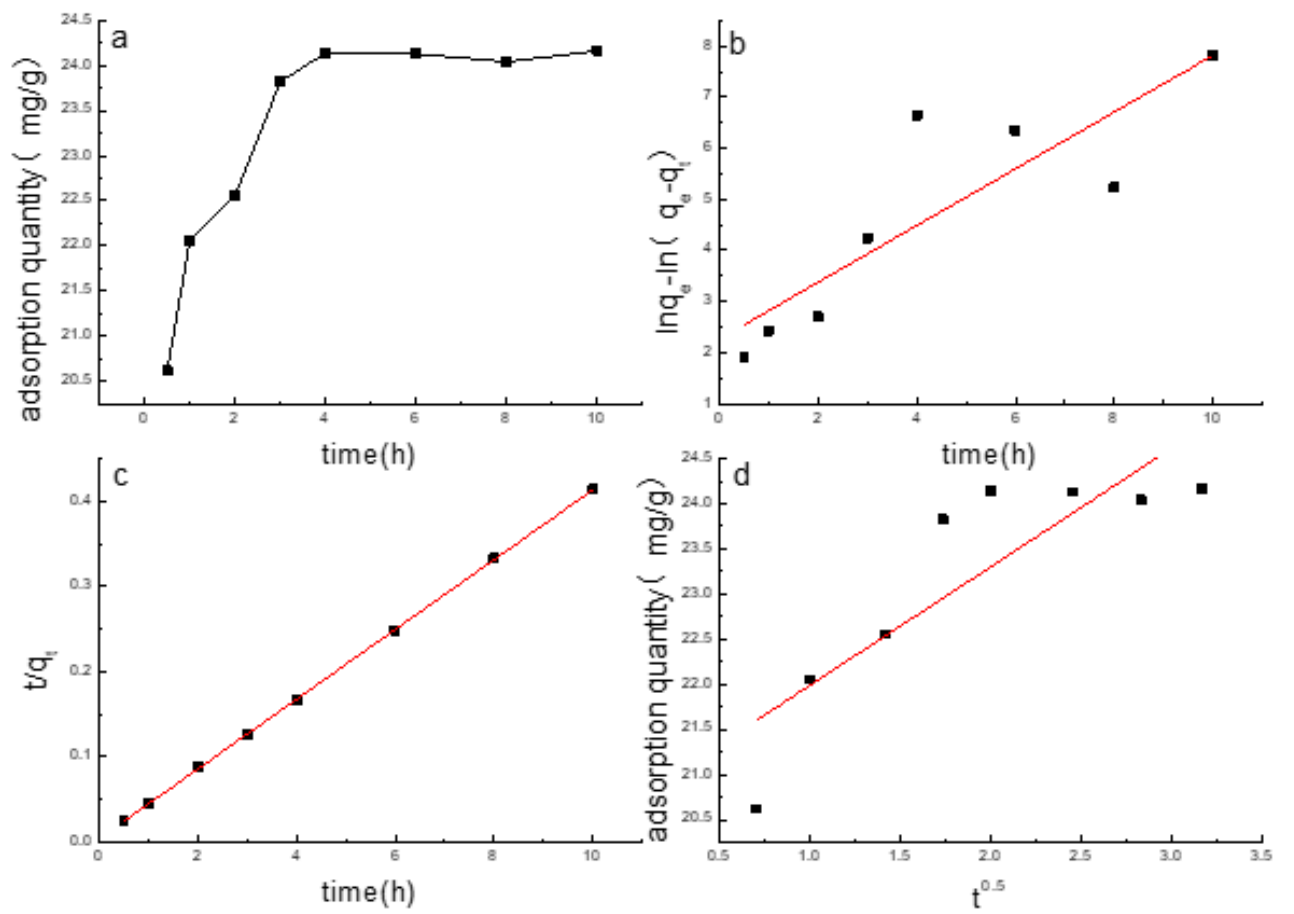

Figure 9: Adsorption kinetics of SDS/sepiolite (a: the relation of adsorption and time, b: pseudo first-order kinetics fitting, c: pseudo first-order kinetics fitting, d: Morries-Wede fitting).

\section{Isotherm of adsorption}

Adsorption isotherm and its fitting results is presented in Figures 10,11,12 and Table's 4 \& 5. The correlation coefficients fitted $\left(\mathrm{R}_{1}{ }^{2}<0.99<\mathrm{R}_{2}{ }^{2}\right)$ and $\mathrm{q}_{\mathrm{m}}$ equaled the saturation adsorption quantity of experiments both indicated adsorption of $\mathrm{RhB}$ with SDS/sepiolite can be well fitted by the Langmuir equation in the experiment examined the range of temperature and concentration. Single saturation adsorption amount and the equilibrium constant b were positively correlated to temperature obtained from Figure 10. It revealed the adsorption process is an endothermic process. Adsorption of RhB with SDS/sepiolite is preferentially adsorbed due to $b>0.1 / n<1$ also showed the adsorption process is chemical adsorption in Table 6 . The correlation coefficients $\mathrm{R}_{1}{ }^{2}$ was positively correlated to $n$ (when the $n<1, R_{1}^{2}$ nearly equal to 1 ) which also indicated adsorption is a monolayer adsorption [24-27].

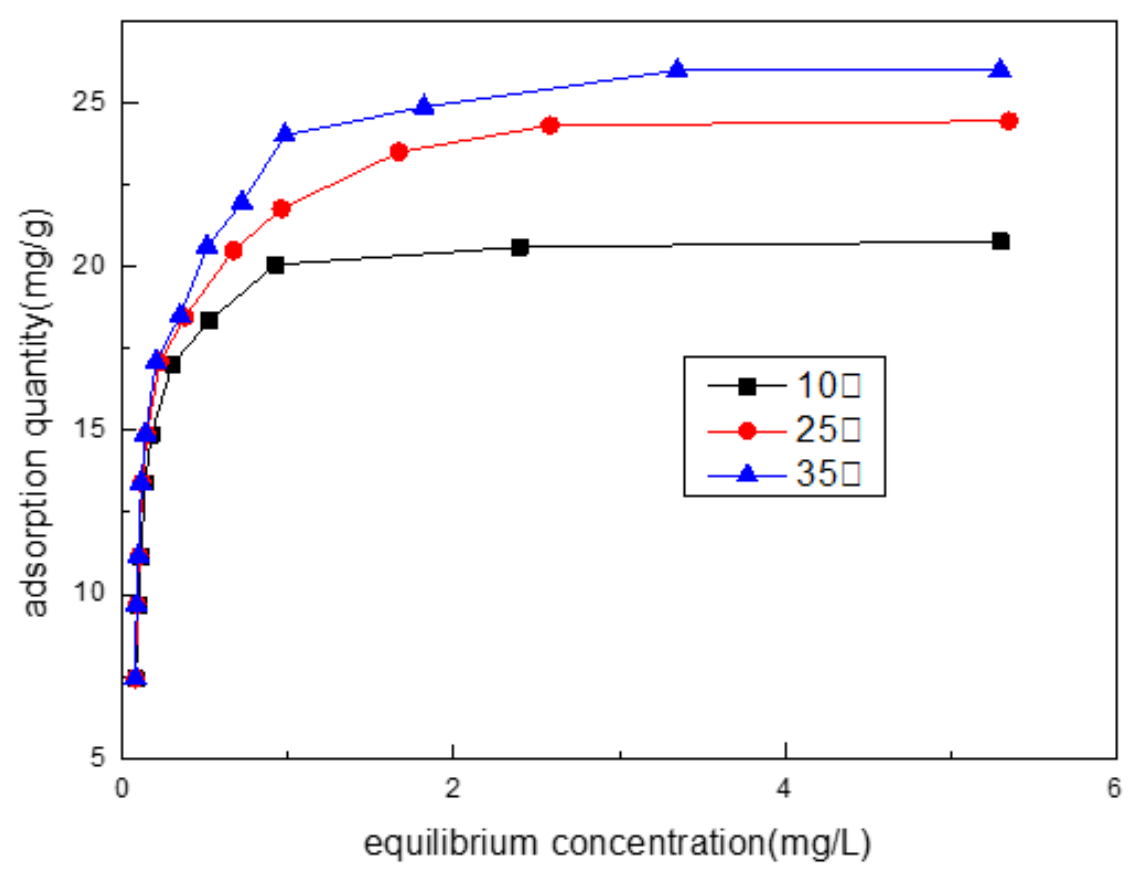

Figure 10: Adsorption isotherm under different temperature. 


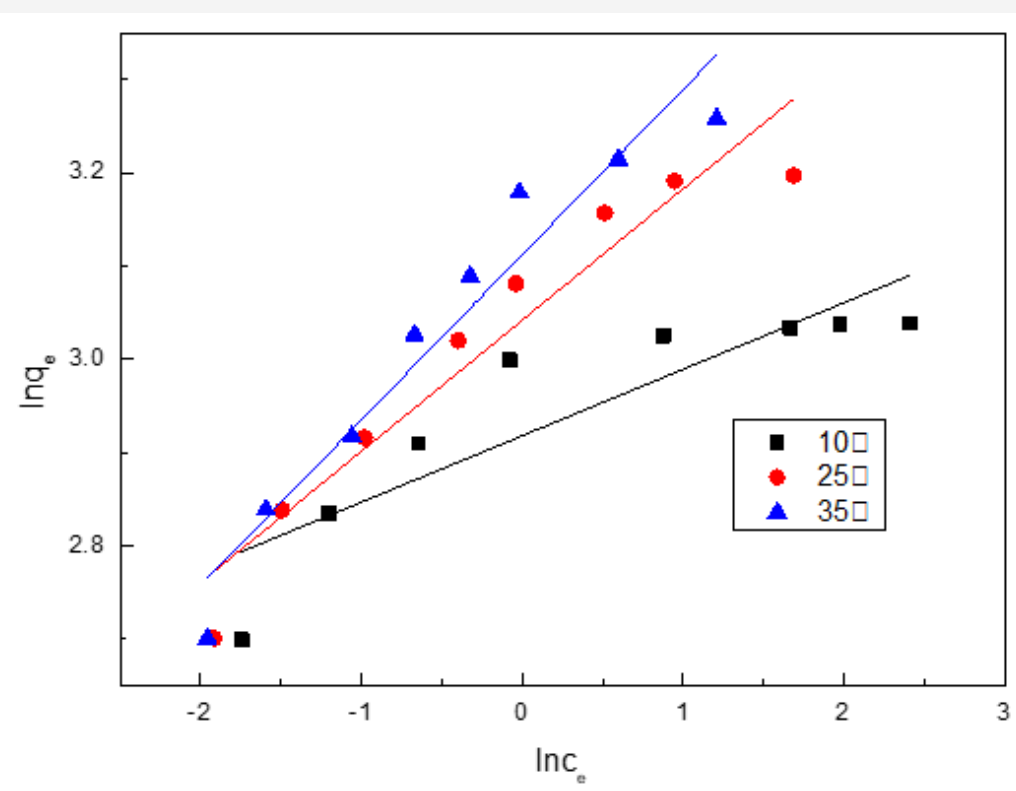

Figure 11: Freundlich linear fitting adsorption isotherm.

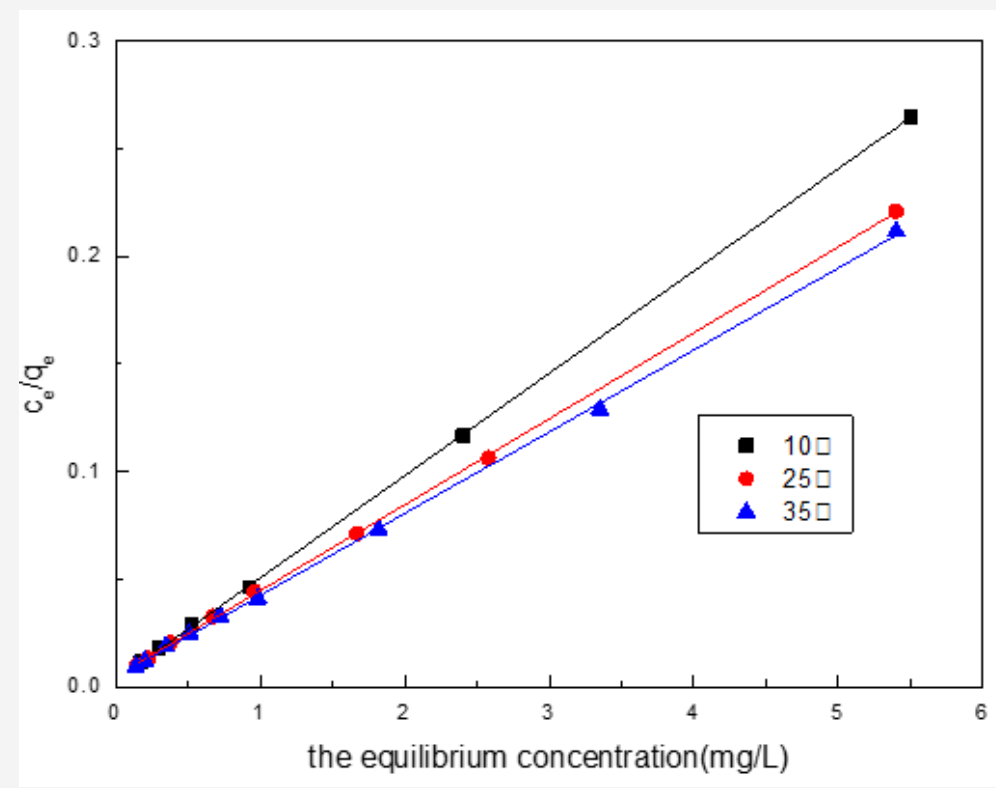

Figure 12: Langmuir linear fitting adsorption isotherm.

Table 4: Adsorption kinetics parameters.

\begin{tabular}{|c|c|c|c|c|c|c|c|c|}
\hline \multirow{2}{*}{ Fitting Type } & \multicolumn{2}{|c|}{ Pseudo-First Order } & \multicolumn{3}{|c|}{ Pseudo-Second Order } & \multicolumn{3}{|c|}{ Morries-Wede } \\
\cline { 2 - 9 } & $\mathbf{K}^{1}$ & $\mathbf{R}^{\mathbf{2}}$ & $\mathbf{K}^{\mathbf{2}}$ & $\mathbf{1 / q e}$ & $\mathbf{R}^{\mathbf{2}}$ & $\mathbf{k p}$ & $\mathbf{c}$ & $\mathbf{R}^{\mathbf{2}}$ \\
\hline Coefficients & 0.5545 & 0.705 & 2.5 & 0.041 & 0.999 & 1.315 & 20.674 & 0.707 \\
\hline
\end{tabular}

Table 5: Freundlich linear fitting parameters.

\begin{tabular}{|c|c|c|c|c|}
\hline Temperature $\left({ }^{\circ} \mathrm{C}\right)$ & Regression Equation & $\mathbf{R}_{\mathbf{1}}{ }^{2}$ & $\mathbf{k}$ & $\mathbf{n}$ \\
\hline 10 & $\mathrm{y}=0.071 \mathrm{x}+2.938$ & 0.753 & 18.878 & 14.085 \\
\hline 25 & $\mathrm{y}=0.141 \mathrm{x}+3.042$ & 0.911 & 20.947 & 7.092 \\
\hline 35 & $\mathrm{y}=0.178 \mathrm{x}+3.112$ & 0.93 & 22.466 & 5.618 \\
\hline
\end{tabular}

Table 6: Langmuir linear fitting parameters.

\begin{tabular}{|c|c|c|c|c|}
\hline Temperature $\left({ }^{\circ} \mathrm{C}\right)$ & Regression Equation & $\mathbf{R 2 2}$ & $\mathbf{q m}(\mathbf{m g} / \mathbf{L})$ & $\mathbf{b}(\mathrm{L} / \mathbf{m g})$ \\
\hline 10 & $\mathrm{y}=0.0476 \mathrm{x}+0.00295$ & 0.996 & 21.008 & 16.136 \\
\hline 25 & $\mathrm{y}=0.0399 \mathrm{x}+0.0047$ & 0.997 & 25.062 & 8.49 \\
\hline 35 & $\mathrm{y}=0.037 \mathrm{x}+0.0052$ & 0.995 & 27.027 & 7.115 \\
\hline
\end{tabular}




\section{Re-adsorption analysis}

In the study of this experiment, the first adsorption quantity was much greater than the second adsorption and the third adsorption quantity (Figure 13). Each adsorption amount is not large, however, the sum of each saturation adsorption amount $(30.39 \mathrm{mg} / \mathrm{L})$ was larger than the maximum adsorption quantity $(24.91 \mathrm{mg} / \mathrm{L})$ under optimal conditions. Desorption generation was appeared in the process of adsorption and some mass RhB adsorbed desorbed in the filtration and drying experiments. It indicated SDS/sepiolite as a reusable sorbent was used in environmental protection.

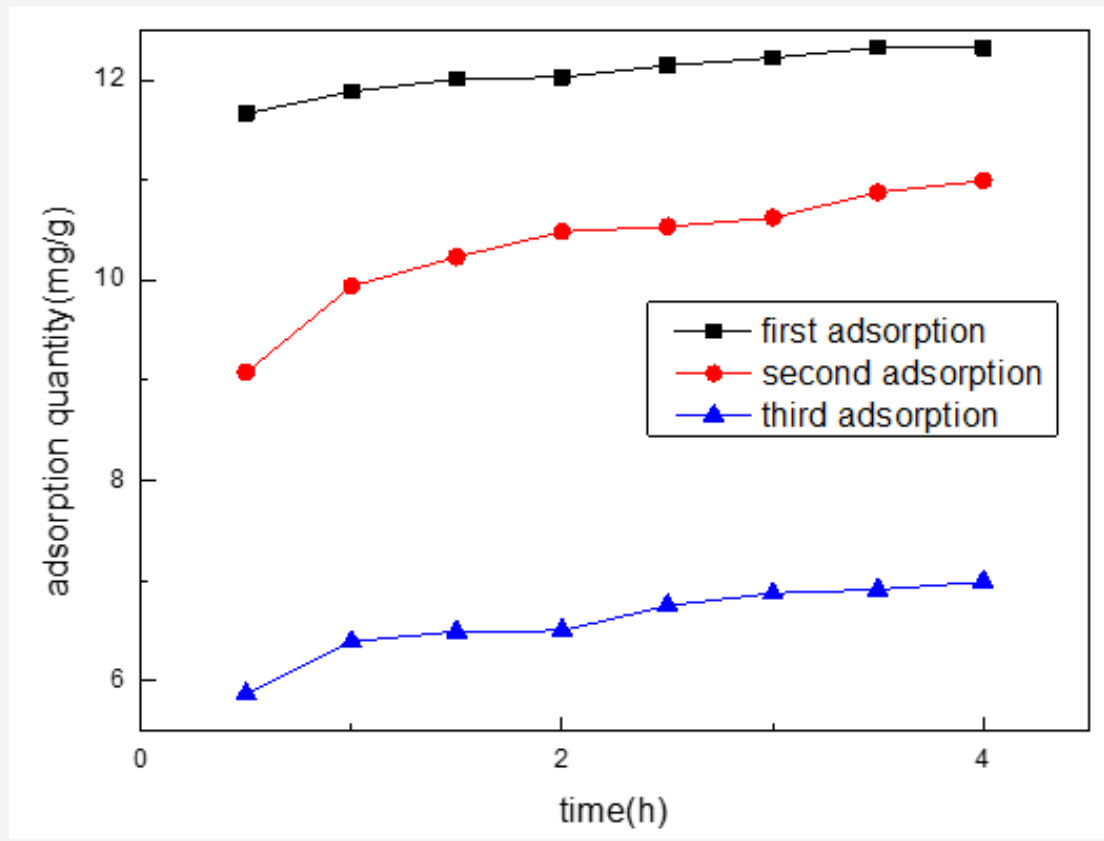

Figure 13: Comparison of the amount of re-adsorption.

\section{Conclusion}

A novel adsorbent SDS/sepiolite composite was successfully prepared. Adsorption properties of SDS/sepiolite indicate that it has a good adsorption capacity in the comparation of adsorbing RhB and Analysis of the specific surface area, morphology, microstructure, chemical structure, chemical bonding substance and functional groups. Maximum adsorption quantity was $24.91 \cdot \mathrm{mg} / \mathrm{L}$ under the optimum conditions $\left(\mathrm{m}_{\mathrm{SDS} / \mathrm{sep}}=0.02 \mathrm{~g}\right.$, $\mathrm{c}_{\mathrm{RhB}}=35 \mathrm{mg} / \mathrm{L}, \mathrm{pH}=3$.) verified by orthogonal experiment. Adsorbing kinetics and adsorption isotherm revealed main adsorption reaction was chemical adsorption and Single adsorbing. Adsorption quantity increases with increasing temperature. Re-adsorption analysis indicated SDS/sepiolite as a reusable sorbent was used in removal of RhB. All results indicated anionic surfactants SDS modified sepiolite primarily to enhance the chemistry adsorption properties of surface. In summary, SDS/sepiolite can as an efficient and low-cost adsorbent used in environmental field.

\section{Acknowledgement}

None.

\section{Conflict of Interest}

No conflict of interest.

\section{References}

1. Chen XF, Dai JF, Shi GF, Li L, Wang GY, et al. (2016) Sonocatalytic degradation of Rhodamine B catalyzed by beta-Bi203 particles under ultrasonic irradiation. Ultrason. Sonochem 29: 172-177.
2. Gao YW, Wang Y, Zhang H (2015) Removal of Rhodamine B with Fesupported bentonite as heterogeneous photo-Fenton catalyst under visible irradiation. Applied Catalysis B-Environmental 178: 29-36.

3. Shen J, Wu Yn, Zhang B, Li F (2015) Adsorption of Rhodamine B dye by biomimetic mesoporous $\mathrm{SiO} 2$ nanosheets. Clean Technologies and Environmental Policy 17: 2289-2298.

4. Marjanovic V, Lazarevic S, Jankovic-Castvan I, Jokic B, Janackovic D, et al. (2013) Adsorption of chromium (VI) from aqueous solutions onto amine-functionalized natural and acid-activated sepiolites. Applied Clay Science 80-81: 202-210.

5. Sevim AM, Hojiyev R, Gul A, Celik MS (2011) An investigation of the kinetics and thermodynamics of the adsorption of a cationic cobalt porphyrazine onto sepiolite. Dyes and Pigments 88(1): 25-38.

6. Tekin N, Kaya AU, Esmer K, Kara A (2012) Adsorption and dielectric properties of poly(1-vinylimidazole) on sepiolite. Applied Clay Science 57: $32-38$.

7. Eren E, Gumus H (2011) Characterization of the structural properties and $\mathrm{Pb}$ (II) adsorption behavior of iron oxide coated sepiolite. Desalination 273(2-3): 276-284.

8. Corma A (2004) Alkali-exchanged sepiolites containing palladium as bifunctional (basic sites and noble metal) catalysts for the Heck and Suzuki reactions. Applied Catalysis A: General 257(1): 77-83.

9. Vico LI (2003) Acid-base behaviour and $\mathrm{Cu} 2+$ and $\mathrm{Zn} 2+$ complexation properties of the sepiolite/water interface. Chemical Geology 198: 213222.

10. Brindley GW (1959) X-ray and electron diffraction data for sepiolite. American Mineralogist 44: 495-500.

11. Letaief S, Grant S, Detellier C (2011) Phenol acetylation under mild conditions catalyzed by gold nanoparticles supported on functional preacidified sepiolite. Applied Clay Science 53: 236-243.

12. Miura A, Nakazawa K, Takei T, Kumada N, Kinomura N, et al. (2012) Acid, base-, and heat-induced degradation behavior of Chinese sepiolite. Ceramics International 38(6): 4677-4684. 
13. Franco F, Pozo M, Cecilia JA, Benitez-Guerrero M, Pozo E, et al. (2014) Microwave assisted acid treatment of sepiolite: The role of composition and "crystallinity". Applied Clay Science 102: 15-27.

14. Duan E, Han J, Song Y, Guan Y, Zhao W, et al. (2013) Adsorption of styrene on the hydrothermal-modified sepiolite. Materials Letters 111: 150-153.

15.Zhang G, Xiong Q, Xu W, Guo S (2014) Synthesis of bicrystalline $\mathrm{TiO}_{2}$ supported sepiolite fibers and their photocatalytic activity for degradation of gaseous formaldehyde. Applied Clay Science 102: 231237.

16. Lazarevic S, Jankovic-Castvan I, Potkonjak B, Janackovic D, Petrovic $\mathrm{R}$ (2012) Removal of $\mathrm{Co}^{2+}$ ions from aqueous solutions using ironfunctionalized sepiolite. Chemical Engineering and Processing-Process Intensification 55: 40-47.

17. Pina-Zapardiel R, Esteban-Cubillo A, Bartolome JF, Pecharroman C, Moya JS (2013) High wear resistance white ceramic glaze containing needle like zircon single crystals by the addition of sepiolite $\mathrm{n}-\mathrm{ZrO}_{2}$. Journal of the European Ceramic Society 33(15-16): 3379-3385.

18. Alan N, Isci S (2014) Surface modification of sepiolite particles with polyurethane and polyvinyl alcohol. Progress in Organic Coatings 77: 444-448.

19. Liu S, Zhu J, Yang Q Xu P, Ge J, et al. (2016) Facile fabrication and enhanced photocatalytic performance of $\mathrm{Ag} @ \mathrm{AgCl}$-activated sepiolite heterostructure photocatalyst. Journal of Materials Science 51: 25652572 .

20. Eren E, Gumus H, Sarihan A (2012) An investigation of the catalytic decomposition of formic acid on raw and manganese oxide coated sepiolite surfaces. Applied Clay Science 62-63: 1-7.
21. Tunc S, Duman O, Kanci B (2012) Rheological measurements of Na-bentonite and sepiolite particles in the presence of tetradecyltrimethylammonium bromide, sodium tetradecyl sulfonate and Brij 30 surfactants. Colloid Surf. A-Physicochem Eng Asp 398: 37-47.

22. Shang J, Liu C, Wang Z, Zachara JM (2011) Effect of Grain Size on Uranium (VI) Surface Complexation Kinetics and Adsorption Additivity. Environ. Sci Technol 45(14): 6025-6031.

23. Shi Z, Di Toro DM, Allen HE, Sparks DL (2013) A General Model for Kinetics of Heavy Metal Adsorption and Desorption on Soils. Environ Sci Technol 47(8): 3761-3767.

24. Shi Z, Di Toro DM, Allen HE, Sparks DL (2013) A General Model for Kinetics of Heavy Metal Adsorption and Desorption on Soils. Environ Sci Technol 47(8): 3761-3767.

25. Soukup J, Jandera P (2014) Adsorption of water from aqueous acetonitrile on silica-based stationary phases in aqueous normal-phase liquid chromatography. Journal of Chromatography A 1374: 102-111.

26. Wu C, Zandavi SH, Ward CA (2014a) Prediction of the wetting condition from the Zeta adsorption isotherm. Physical Chemistry Chemical Physics 16: 25564-25572.

27. Wu Y, Luo H, Wang H, Zhang L, Liu P, et al. (2014b) Fast adsorption of nickel ions by porous graphene oxide/sawdust composite and reuse for phenol degradation from aqueous solutions. J Colloid Interface Sci 436: 90-98. 